\title{
Gêneros textuais nos livros didáticos do Ensino Médio
}

\section{Text genres in Brazilian high school textbooks}

https://doi.org/10.34112/2317-0972a2018v36n72pg9-114

Juvenal Zanchetta JR. ${ }^{1}$

Keli Mazzo ${ }^{2}$

Erika Nogueira Menegon ${ }^{3}$

RESUMO: Este artigo analisa o conjunto de textos de terceiros constantes em livros didáticos aprovados pelo MEC em 2015, dentro do Programa Nacional do Livro Didático para o Ensino Médio (PNLEM). Partindo da referência de gênero textual amparada pelas diretrizes curriculares nacionais, avaliam-se as coleções mais distribuídas no país, observando-se os gêneros empregados, os domínios discursivos a que os gêneros se referem, as condições de apresentação e finalidades dos textos. Observam-se ainda características que ajudam a explicar o sucesso da coleção mais distribuída no PNLEM/2015.

PALAVRAS-CHAVE: Livro didático; gêneros textuais; textos.

ABSTRACT: This article analyzes the set of third-party texts in textbooks approved by the MEC in 2015, within the Programa Nacional do Livro Didático para o Ensino Médio (PNLEM). Based on the concept of textual gender supported by the national curricular guidelines, the most distributed textbooks collections in the country are evaluated, observing the genres, the discursive domains, the presentation conditions and the texts' purposes. There are also aspects that explain the success of the most distributed collection in PNLEM/2015.

KEYwords: Textbook; textual genres; texts.

1. Faculdade de Ciências e Letras de Assis, Assis, São Paulo, Brasil.

2. Faculdade de Ciências e Letras de Assis, Assis, São Paulo, Brasil.

3. Secretaria da Educação do Estado de São Paulo, Assis, São Paulo, Brasil. 
Apresentação

O presente artigo reporta análise acerca dos textos empregados em oito coleções de livros didáticos para o Ensino Médio (LD) entre as mais distribuídas dentro do PNLEM-2015 (abarcam cerca de 90\% das escolhas dos professores). Buscamos primeiramente caracterizar a noção de gênero textual, para, depois: a) definir os gêneros e quantificar os textos verbais e não verbais empregados, produzidos por terceiros; b) avaliar o uso dos gêneros mais recorrentes entre esses textos; c) especular sobre razões que explicariam, do ponto de vista do emprego dos gêneros textuais, o sucesso de Português: Linguagens (PL) (CEREJA; COCHAR, 2013), a coleção mais indicada entre os professores (cerca de $30 \%$ das escolhas).

\section{NoÇÃo DE GÊNERO TEXTUAL}

A perspectiva adotada para o estudo das noções de texto e de gênero é a do interacionismo sociodiscursivo (BRONCKART, 1999; SCHNEUWLY; DOLZ, 2004), voltada ao estudo das relações entre linguagem e desenvolvimento humano, atribuindo à linguagem papel decisivo para o funcionamento e para o desenvolvimento psíquico dos indivíduos, e também para as atividades que enformam a experiência humana. As relações entre o homem e o mundo seriam "semiotizadas" e conformariam "signos" linguísticos (BRONCKART, 1999) que se desenvolvem em diferentes "domínios discursivos" (relativos às diversas áreas da ação humana, como a familiar, a religiosa, a do trabalho etc.) e se manifestam por meio de "gêneros textuais" (tomados como "construtos históricos", cuja forma e propósitos comunicativos decorrem dos usos que as pessoas fazem deles) (MARCUSCHI, 2008).

Os Parâmetros Curriculares Nacionais (PCN) para o ensino de língua materna (BRASIL, 1997; 1998) alinham-se com aquela perspectiva teórica, principalmente porque, nos dois casos, há destaque para a noção bakhtiniana de linguagem como processo dialógico, ideológico, histórico (BAKHTIN, 1992; MARCUSCHI, 2008;

4. Português: Linguagens (PL) (CEREJA; MAGALHÃES, 2013); Novas Palavras (NP) (AMARAL et al., 2013); Português: Contexto, Interlocução e Sentido (PCIS) (ABAURRE; ABAURRE; PONTARA, 2013); Língua Portuguesa: Linguagem e Interação (LI) (FARACO; MOURA; MARUXO Jr., 2014); Português: Linguagens em conexão (PLCO) (SETTE; TRAVALHA; STARLING, 2013); Ser Protagonista: Língua Portuguesa (SP) (RAMOS, 2013); Viva Português (VP) (CAMPOS; CARDOSO; ANDRADE, 2014); Português: língua e cultura (PLC) (FARACO, 2013). 
MORATO, 2011). Os textos materializam-se e se diferenciam uns dos outros a partir de critérios não apenas formais relacionados às "escolhas feitas pelo autor entre as possibilidades oferecidas pela língua”, mas também sociais, incluindo o contexto de produção e de circulação, as estratégias comunicativas e aspectos intertextuais (BRASIL, 2006, p. 60). Em projetos governamentais mais recentes, como no Pacto Nacional pela Alfabetização na Idade Certa (PNAIC), o interacionismo sociodiscursivo aparece textualmente nas diretrizes para o ensino de língua materna nas primeiras séries do EF (BRASIL, 2012a; 2012b). Segundo Marcuschi (2008, p. 155), em definição sobre gênero textual próxima do dialogismo bakhtiniano, do interacionismo e das propostas oficiais:

Gênero textual refere os textos materializados em situações comunicativas recorrentes. Os gêneros textuais são os textos que encontramos em nossa vida diária e que apresentam padrões sociocomunicativos característicos definidos por composições funcionais, objetivos enunciativos e estilos concretamente realizados na integração de forças históricas, sociais, institucionais e técnicas. Em contraposição aos tipos, os gêneros são entidades empíricas em situações comunicativas e se expressam em designações diversas, constituindo em princípio listagens abertas. [...] Como tal, os gêneros são formas textuais escritas ou orais bastante estáveis, histórica e socialmente situadas. (2008, p. 155).

A maioria das coleções avaliadas lança mão do conceito de gênero textual. Bakhtin é o autor comum às coleções, embora a maioria delas afirme se escudar em autores que levaram adiante as ideias do pensador russo, como Bronckart, Schnewly e Dolz. A perspectiva ora adotada para a análise, portanto, não difere daquela empregada pelos próprios manuais.

Mas o emprego da noção de gênero textual, nesta pesquisa, enfrenta problemas, a começar por aqueles relacionados aos textos não verbais, tomados aqui como textos cujas proposições de sentido estão ancoradas principalmente na imagem, como no caso de uma pintura, ou cujos sentidos se enformam a partir da união entre a imagem e o texto verbal, como no caso de uma foto jornalística acompanhada de legenda. Esses textos apresentam mecanismos de produção e de circulação análogos aos dos textos verbais, além de serem compreendidos, em grande parte, graças a convenções sociais determinadas. A charge, por exemplo, propõe significados para uma questão social ou política inerente a um determinado contexto e só pode ser plenamente compreendida por leitores que conheçam tal contexto. A charge de 
Jean Galvão, que reproduzia a boneca Emília surpresa por se ver com um pedaço de pano costurado em sua bocas ${ }^{5}$, pode ser compreendida se o leitor souber: a) quem é a personagem; b) quem foi Monteiro Lobato; c) características da obra desse escritor; d) qual questão judicial está ali implicada ${ }^{6}$; e) em que contexto a charge foi publicada; f) onde foi publicada. O conhecimento de tais informações levaria o leitor a compreender a charge, a opinião do chargista sobre o tema e a inferir mesmo a opinião do jornal que publicou o texto.

Embora apresentem características textuais próximas àquelas propostas por Bronckart (1999) e Marcuschi (2008), os textos imagéticos são pouco enfrentados por esses autores. A fotografia, por exemplo, pode ser tomada como domínio discursivo (graças aos diversos requisitos formais, comunicacionais e situacionais nela implicados) ou como gênero textual maior que se desdobra em diversos gêneros mais específicos, inseridos em domínios discursivos como o do jornalismo (o fotojornalismo), o da propaganda (a fotografia relacionada a produtos ou ao turismo, por exemplo) e o das relações interpessoais (as fotos de família ou de relações de amizade). A fotografia pode ainda servir como suporte para outros gêneros (a foto de uma instalação artística ou de uma escultura). A presente pesquisa não tem a pretensão de discutir tais limitações, mas a ressalva é necessária porque diversas escolhas foram feitas nesse terreno movediço.

Outro problema decorre do exercício de adaptação dos textos de terceiros empregados nas obras didáticas, o que leva à necessidade de maior reflexão acerca de aspectos relacionados à noção de gênero. Um texto de propaganda concebido para uma revista ou jornal, cujo público tinha características sociais, econômicas e políticas específicas, uma vez inserido no livro didático, deixa em segundo plano o objetivo de promover ou vender um produto, para enquadrar-se em uma finalidade pedagógica e direcionada a um público distinto dos consumidores pensados inicialmente. Uma reportagem publicada primeiro num jornal tende a ser reproduzida apenas em seu texto principal no livro didático (diversas vezes adaptado): somem os gráficos, os textos de apoio, as fotografias, a disposição na página do jornal, o próprio suporte do jornal, o contexto em que se deu a publicação original. O público leitor inicial da reportagem dá lugar a estudantes, quase sempre desconhecedores

5. Folha de S. Paulo, 12 de setembro de 2012, p. A2.

6. Em 2012, chegou ao Supremo Tribunal Federal processo que exigia a proibição da distribuição, pelo governo federal, do livro Caçadas de Pedrinho, por supostas sugestões racistas contidas na obra. 
do jornal e das suas características. Existe, então, algum grau de comprometimento dos textos originais quando transportados para o livro didático não enfrentado aqui.

Decorrentes dessas questões, outras escolhas também precisam ser circunstanciadas. Como primeira regra, procuramos agrupar os textos de acordo com as características mais evidentes do gênero original. No entanto, em alguns casos, mostrou-se mais viável a aproximação por domínios discursivos (casos explicitados adiante). Houve situações ainda em que os textos foram reunidos a partir de sua finalidade: é o caso das 'ilustrações', que, em nossa tabulação, reúnem diferentes gêneros, mas, nas coleções avaliadas, mostram-se como textos não verbais, com função documental ou acessória de conteúdos presentes nos textos verbais. Outros critérios são explicados em momento oportuno. Os quadros apresentados, enfim, refletem apenas parte das características de uso dos gêneros textuais pelas coleções, mas procuram, a partir do referencial teórico explicitado, equivalências entre os textos presentes nessas obras, de modo a possibilitar a comparação entre elas.

\section{TEXTOS NÃO VERBAIS NAS COLEÇÕES}

Apresentamos inicialmente a lista de gêneros textuais não verbais. Os números apresentados não são definitivos, por conta da dificuldade de se precisar o gênero de diversos textos, muitas vezes não identificados ou com funções pouco específicas, ou ainda por conta da própria imprecisão da noção de gênero aplicada a textos não verbais. Houve também discrepância de avaliação, por vezes significativa, entre os avaliadores. No entanto, erros na somatória não modificam substancialmente o quadro geral. A análise daí decorrente, por sua vez, está baseada em características mais evidentes observadas a partir do confronto entre as coleções, o que também minimiza o peso de eventuais divergências nos números.

\begin{tabular}{|l|r|r|r|r|r|r|r|r|}
\hline & NP & PCIS & PL & VP & LI & SP & PLC & PLCO \\
\hline Ilustração & 144 & 328 & 173 & 276 & 451 & 402 & 127 & 433 \\
\hline Arte & 295 & 128 & 219 & 99 & 69 & 18 & 35 & 110 \\
\hline Fotografia & 96 & 67 & 229 & 108 & 174 & 110 & 57 & 69 \\
\hline Tira & 74 & 233 & 100 & 17 & 08 & 101 & - & 63 \\
\hline Propaganda & 30 & 107 & 77 & 19 & 08 & 29 & - & 19 \\
\hline Foto autor/celebridade & 25 & 68 & 58 & 84 & 159 & 64 & 12 & 50 \\
\hline
\end{tabular}




\begin{tabular}{|l|r|r|r|r|r|r|r|r|}
\hline Capa & 46 & 53 & 88 & 44 & 145 & 88 & 05 & 37 \\
\hline Fotojornalismo & 16 & 31 & 05 & 21 & 10 & 65 & 03 & 09 \\
\hline Charge & 15 & 12 & 02 & 07 & 01 & 07 & 01 & 01 \\
\hline Cartum & 11 & 13 & 13 & 01 & 01 & 10 & - & 04 \\
\hline Infografia & 04 & 40 & 16 & 06 & 10 & 11 & 02 & 03 \\
\hline Cena & 06 & 30 & 70 & 61 & 85 & 48 & - & 26 \\
\hline HQ & - & - & - & 01 & - & - & - & - \\
\hline
\end{tabular}

Tabela 1: gêneros de textos não verbais encontrados nos $L D$

Arte: optamos pela sugestão de domínio discursivo, agrupando reproduções de pinturas e fotos de outras obras de arte, como esculturas e instalações, cujo propósito, de maneira geral, é apresentar ou ilustrar tendências estéticas e artistas determinados. Do total de manifestações artísticas, grande parte é formada por pinturas; o restante são imagens de esculturas.

Capas: reproduções fotográficas de capas de discos, CDs, DVDs e livros. Neste caso, embora não se trate aqui de um gênero textual, mas sim de um 'lugar' (MARCUSCHI, 2008), as capas foram reunidas em um só item por conta da alta incidência nas diversas coleções.

Cenas: fotografias de filmes, peças teatrais, novelas e outras produções artísticas, muitas delas utilizadas para a própria divulgação dos produtos. Poderiam ser incluídas entre as imagens de propaganda, mas foram destacadas por conta da recorrência em várias coleções.

Fotografias: imagens envolvendo paisagens, situações cotidianas, pessoas anônimas, lugares ou objetos.

Fotojornalismo: imagens jornalísticas, publicadas em jornais contemporâneos e ainda cenas ilustrativas de eventos ou de momentos históricos determinados.

Ilustrações: imagens diversas, desde reproduções em fac-símile de páginas de jornal e caricaturas de autores, até desenhos que servem de adereço a textos poéticos ou atividades. Embora haja nesta rubrica vários gêneros, predomina a finalidade de adereço (maior parte) ou de ilustração documental de temas tratados principalmente a partir da linguagem verbal.

Infografia: mapas, gráficos isolados ou associados a textos verbais que procuram sintetizar a evolução de uma determinada questão, no tempo e no espaço. 
Propaganda: também optamos pelo agrupamento a partir do domínio discursivo. Foram reunidas e inseridas nesta tabela por disporem da imagem como elemento pronunciado, além da mensagem (verbal e não verbal) de cunho apelativo. A maioria são peças de propaganda publicadas em meio impresso, embora haja também posters e cartazes?.

Não foram computados os textos referentes às sugestões de leitura propostas pelas coleções, por conta da diversidade de alternativas, o que dificultou a comparação das estratégias. Em alguns livros, há apenas textos telegráficos sugerindo esta ou aquela leitura; em outros, há seções inteiras dedicadas a tal propósito. Nesse sentido, destaquem-se as coleções PL e PCIS, que, além de seções determinadas para a pesquisa em outros suportes, também são robustas em termos de pesquisa iconográfica. Também não foram computadas imagens que fazem parte de exercícios extraídos de exames vestibulares, diferentemente de imagens empregadas em exercícios produzidos pelos próprios autores, que foram computadas (quando produzidas por terceiros).

Ilustrações, fotografias diversas e, em número mais discreto, reproduções de obras de arte, tiras e propagandas são os gêneros com maior volume em quase todas as coleções, perfazendo mais da metade do total de textos não verbais de terceiros apresentados. Tal característica reforça o caráter de mosaico que se pretende nos livros, oferecendo-se diversas "entradas" nas unidades didáticas. Por outro lado, as imagens são por si estratégia para chamar a atenção de leitores iniciantes, além de comporem projetos gráficos mais atraentes.

No entanto, observam-se problemas históricos atrelados ao uso das imagens. $\mathrm{O}$ primeiro deles diz respeito ao discreto número de domínios e gêneros empregados, principalmente se se leva em conta o fato de que boa parte dos textos se apresenta a partir de fotografias. Embora os avanços gráficos desde a década de 1970 tenham permitido o uso mais intenso de ilustrações, a variedade de gêneros sempre se mostrou diminuta e acessória ao tratamento do texto verbal. Mesmo hoje são raras as unidades didáticas centradas especificamente em gêneros não verbais.

Em segundo lugar está a consistência documental das imagens. No caso da rubrica 'ilustrações', em alguns casos, as imagens acrescentam detalhes ou servem como apoio acerca das noções tratadas nos gêneros escritos, mas a maior parte do

7. Eles aparecem apenas nas coleções Novas Palavras e Viva Português. 
conjunto cumpre apenas a função de adereço, com conteúdo informativo mínimo. $\mathrm{Na}$ casa da centena em diversas coleções, tais ilustrações não vão além de informação superficial, muitas vezes atrelada a uma sugestão encontrada em um texto literário e, sobretudo, poético, para chamar a atenção do leitor e, em diversas situações, para antecipar ou propor algum efeito estético. Repete-se outro problema atrelado aos textos não verbais nos livros didáticos: mesmo citadas em termos de autoria, as ilustrações são pouco exploradas como textos autônomos.

As fotografias exercem, até certo ponto, papéis semelhantes. Em que pese o fato de as coleções, em alguns momentos, fazerem uso de fotos histórico-documentais, a maioria das imagens ocupa lugar secundário. São comuns reproduções de pessoas em situações cotidianas, mas sem qualquer menção à identidade dos sujeitos representados e também sem legendas explicativas ${ }^{8}$. O número discreto de fotos jornalísticas em quase todas as coleções é também representativo do aproveitamento raso de um gênero fundamental no mundo contemporâneo.

Apenas algumas reproduções de obras de arte ocupam espaços de destaque e são acompanhadas de análise detalhada. A grande maioria das obras aparece em boxes minúsculos, impedindo a observação de detalhes. Por conta da descrição mínima de autoria e filiação estética, tais imagens funcionam, quando muito, como links, levando o leitor a buscar a imagem em outro suporte.

A tabela mostra com alguma clareza carência observada pelo próprio Guia de Livros Didáticos (BRASIL, 2014): a falta de textos mais próximos do universo juvenil. Com exceções pontuais, mesmo os quadrinhos (tiras, charges, cartuns e HQs) e propagandas, gêneros com grande circulação na mídia, também aparecem em número comedido. Estaria aí uma primeira explicação para o êxito da coleção PL: o uso destacado e equilibrado (em relação às demais obras) dos gêneros não verbais. À exceção de HQs (mais presentes em coleções voltadas para o EF), charges e cartuns (cuja ausência é compensada por tiras em grande número), a coleção PL lança mão de universo largo de textos não verbais, dentro de um conjunto de gêneros comum a todas as coleções. Vale lembrar que as coleções PL e PCIS também recorrem às imagens para organizar os conteúdos temáticos. É o caso do uso reiterado de infográficos para a explicação de movimentos literários. Quadros detalhados

8. A prática de não nomear personagens fotografados ao leitor não se restringe aos livros didáticos. Basta observar a absoluta ausência de referências nominais em fotos e vídeos publicados na imprensa, quando estes reportam modelos, no campo da moda. 
com informação evolutiva são acompanhados também de imagens, para ajudar o leitor a compreender o percurso de uma determinada questão9.

\section{TEXTOS VERBAIS}

No elenco de textos verbais, excluíram-se a narrativa introdutória e de amarração disposta em cada unidade temática, as explicações gramaticais, as proposições de atividades, os exercícios produzidos pelos autore ${ }^{10} \mathrm{e}$ os reproduzidos de provas externas. A fragmentação dos textos contribui para situações duvidosas, como, por exemplo, para distinguir nota, notícia, reportagem e mesmo fragmento de texto de divulgação científica. Tal situação ainda se agrava pelo fato de, em inúmeras oportunidades, os autores das coleções identificarem os enunciados apenas como "textos". Em razão disso e das mesmas razões apontadas na tabulação de textos não verbais, os números apresentados aqui também não são definitivos. Discrepâncias mais sensíveis foram encontradas entre os gêneros com menor incidência. Erros nos números individuais, porém, não comprometem a análise, pois esta se baseia em características mais evidentes observadas no confronto entre as coleções.

\begin{tabular}{|l|r|r|r|r|r|r|r|r|}
\hline & \multicolumn{1}{|c|}{ NP } & \multicolumn{1}{c|}{ PCIS } & \multicolumn{1}{c|}{ PL } & \multicolumn{1}{c|}{ VP } & \multicolumn{1}{c|}{ LI } & \multicolumn{1}{c|}{ SP } & PLC & PLCO \\
\hline Poesia & 196 & 243 & 248 & 171 & 124 & 214 & 101 & 231 \\
\hline Romance & 73 & 125 & 34 & 46 & 61 & 106 & 23 & 61 \\
\hline Verbete & 48 & 42 & 138 & 11 & 09 & - & - & 51 \\
\hline Artigo & 70 & 44 & 40 & 30 & 18 & 39 & 21 & 23 \\
\hline Crônica & 29 & 33 & 14 & 14 & 10 & 29 & 21 & 17 \\
\hline Auto/biografia & 60 & 117 & 28 & 05 & 02 & 01 & 21 & 04 \\
\hline Nota/Notícia & 36 & 24 & 27 & 21 & 21 & 39 & 17 & 28 \\
\hline Conto & 17 & 12 & 12 & 16 & 36 & 35 & 17 & 20 \\
\hline Canção & 13 & 14 & 09 & 25 & 16 & 23 & 03 & 08 \\
\hline Teatro & 04 & 07 & 06 & 05 & 04 & 08 & - & 03 \\
\hline Entrevista/depo & 03 & 03 & 01 & 16 & 06 & 14 & 05 & 09 \\
\hline Reportagem & 02 & 09 & 08 & 08 & 07 & 23 & 10 & 11 \\
\hline
\end{tabular}

9. As imagens que fazem parte desses infográficos não foram computadas individualmente, algo que acrescenta mais volume e cuidado dessas coleções com a iconografia empregada.

10. Exceto em relação aos textos verbais e não verbais de terceiros, eventualmente empregados nesses exercícios. 


\begin{tabular}{|c|c|c|c|c|c|c|c|c|}
\hline Resenha/Crítica & 09 & 04 & 03 & 16 & - & $\mathrm{O} 2$ & $\mathrm{O} 2$ & $\mathrm{O} 3$ \\
\hline Cordel & - & - & 01 & 07 & 01 & 01 & - & - \\
\hline Doc. Histórico & 06 & 10 & - & 03 & 07 & - & - & - \\
\hline Sermão & $\mathrm{O} 2$ & 04 & 05 & 01 & $\mathrm{O} 2$ & - & - & - \\
\hline Relato & 01 & $\mathrm{O} 2$ & - & 05 & 06 & $\mathrm{O} 3$ & $\mathrm{O} 2$ & - \\
\hline Carta & $\mathrm{O} 3$ & 07 & 10 & 06 & $\mathrm{O} 3$ & 04 & 01 & 04 \\
\hline Anedota & 16 & 04 & $\mathrm{O} 2$ & - & - & - & - & 03 \\
\hline E-mail & 04 & - & 01 & - & - & - & - & - \\
\hline Sentença & 01 & - & - & - & - & - & - & - \\
\hline Manifesto & 05 & 01 & $\mathrm{O} 2$ & $\mathrm{O} 2$ & $\mathrm{O} 2$ & - & - & $\mathrm{O} 3$ \\
\hline Manual & 01 & $\mathrm{O} 3$ & - & 01 & 02 & - & - & - \\
\hline Hino & 01 & - & - & - & - & - & - & 01 \\
\hline Bilhete & 01 & - & - & - & - & - & - & - \\
\hline Receita & 01 & 01 & $\mathrm{O} 2$ & - & 01 & - & - & - \\
\hline Diário & 05 & - & - & - & 04 & - & - & 01 \\
\hline Relatório & 05 & 01 & - & - & - & - & - & - \\
\hline Prefácio & 01 & - & - & - & - & - & - & - \\
\hline Fábula & 01 & - & $\mathrm{O} 2$ & 01 & 01 & - & $\mathrm{O} 2$ & - \\
\hline Auto & - & - & - & - & 01 & - & - & 01 \\
\hline Telegrama & 01 & - & - & - & - & - & - & - \\
\hline Epístola & - & - & 01 & - & 01 & - & - & - \\
\hline Lei & - & - & - & - & 01 & - & - & - \\
\hline Roteiro filme & - & - & - & - & 01 & - & - & - \\
\hline Discurso & - & - & - & - & 01 & - & - & - \\
\hline Currículo & - & - & - & - & 01 & - & - & - \\
\hline Parábola & - & - & - & - & 01 & - & - & - \\
\hline Conversa & - & - & - & - & $\mathrm{O} 2$ & - & - & - \\
\hline Prólogo & - & - & - & - & 01 & - & - & - \\
\hline Novela & - & - & - & - & $\mathrm{O} 2$ & - & - & - \\
\hline Lendas/mitos & - & - & - & - & 04 & - & - & - \\
\hline Debate & - & - & - & - & 01 & - & - & - \\
\hline Horóscopo & - & - & - & - & 01 & - & - & - \\
\hline
\end{tabular}

Tabela 2: Gêneros verbais presentes nas coleções 
Poesia: reunidos aqui vários gêneros poéticos, desde a cantiga até o haicai. Exceção foi feita ao cordel, em razão da extensão, algo que, em geral, demanda o trabalho de unidades didáticas inteiras, diferentemente de boa parte dos poemas, curtos ou inseridos em fragmentos.

Artigos: agrupados os textos deliberadamente opinativos, de editoriais a artigos de opinião, publicados originariamente em jornais e revistas.

Cartas: desde cartas de leitores até a correspondência particular entre indivíduos. Quando marcadamente o documento assumiu outro papel, como no caso da Carta de Pero Vaz de Caminha, a opção adotada foi por anotar tal documento como texto de cunho histórico.

Verbetes: denominação adotada para caracterizar os fragmentos de textos extraídos de obras diversas e voltados, no livro didático, a explicar termos, noções, conceitos ou personagens inclusos em temáticas abordadas nas unidades didáticas.

Auto/biografia: fragmentos de textos de cunho biográfico.

Nota/notícia: não bastasse a dificuldade de se distinguir nota e notícia, pois ambas se diferenciam basicamente por conta da extensão textual, o agrupamento deu-se também por conta da fragmentação, característica comum na apresentação desses textos no livro didático.

Resenha/crítica: reunidos aqui os fragmentos de textos analíticos sobre obras diversas.

A semelhança e a limitação das coleções em termos de domínios discursivos selecionados são traços visíveis. O Guia/2015 (BRASIL, 2014) destaca lacunas importantes, como a ausência de literatura não canônica, de textos jornalísticos e de divulgação científica, de textos multimodais e de gêneros juvenis e do universo juvenil. Mas as ausências parecem ser ainda maiores. Embora os textos apresentados tenham efetiva circulação social (uma das regras do PNLEM), apenas três grandes domínios são tratados: o literário (mais de 50\% do total de textos ${ }^{11}$ ), o midiático (30\% dos textos) e, com frequência menor, os textos interpessoais (até $20 \%$ dos textos). Por literatura, compreendem-se os textos com pretensões estéticas, pertencentes ao cânone acadêmico e chancelados por críticos de arte e participantes do sistema literário, como diz Cândido (1985). Por mídia, compreende-se o conjunto dos meios de comunicação de massa (como a televisão, o jornal impresso, as revistas e os sítios de informação

11. Com exceção da coleção LI, em que os textos literários formam $40 \%$ do conjunto, com maior presença de textos midiáticos. A coleção PL, embora apresente poucos textos midiáticos verbais conta com um número bastante grande de textos midiáticos não verbais. 
na internet, entre outros) e também os meios virtuais, originados de empresas ou de organizações voltadas à comunicação de massa ${ }^{12}$. Entre os demais gêneros, predominam aqueles comuns à comunicação ligeira entre as pessoas. Outros domínios ficam de fora ou são tratados de maneira isolada, como os textos do mundo do trabalho, do comércio, da saúde, da burocracia institucional, entre outros tantos.

A divisão por domínios, entretanto, não implica tratamento programático e que observe a inserção dos textos no mundo, com possível exceção dos textos literários. A apresentação desses textos está mais atenta à progressão estabelecida pela historiografia, comum desde as antologias que chegaram aos anos 1970, e menos em mostrar como a literatura está inserida nas manifestações culturais contemporâneas. A ligação com o mundo de hoje é feita de maneira secundária, por meio do uso esparso de textos de apoio, como canções ou outras obras contemporâneas com temática ou forma vizinha à dos movimentos literários mais distantes no tempo e no espaço.

O enfrentamento dos textos midiáticos é difuso, guardando-se apenas a regra de apresentar antes textos com estrutura composicional mais simples, como notas jornalísticas e notícias, para, depois, operar com reportagens. Em parte por conta do esquematismo, esses textos servem para exercícios de leitura e compreensão acerca de temas cotidianos e também como pretexto para a produção escrita pelos estudantes. Os textos midiáticos não são observados dentro do cenário social e político em que são produzidos (ou em seu domínio discursivo), dificultando a percepção acerca do veículo midiático (o jornal ou a revista) e mesmo da mídia como agentes culturais importantes na vida contemporânea, responsáveis pela sugestão de temas, pontos de vista, tendências e comportamentos.

A fragmentação é determinante também na apresentação dos textos. Entre os gêneros literários, cerca de metade dos textos ainda aparece em excertos. Mesmo em relação a gêneros compreensivelmente recortados, como romances e peças teatrais, mas também em contos e crônicas, os fragmentos utilizados muitas vezes servem mais à explicação da característica historiográfica, temática ou informativa do que à possibilidade de fruição estética. Entre os textos midiáticos, mais da metade aparece em fragmentos, dificultando a visualização integral e também a observação do texto no cenário em que foi publicado originariamente. Os textos interpessoais, em

12. Embora parte da mídia, o suporte livro, impresso ou virtual, por onde circulam os textos literários, será tratado em categoria distinta. Isso ocorre em razão do espaço privilegiado que a escola brasileira confere aos gêneros literários desde o século 19, diferentemente dos demais gêneros midiáticos, que passam a ter espaço nos livros didáticos nacionais apenas a partir da década de 1970. 
geral curtos, tendem a aparecer de maneira integral, embora também isolados de contexto mais amplo.

A configuração das unidades didáticas e a seleção de textos parecem, enfim, tomar certo roteiro comum a obras didáticas publicadas desde 1970. Seguindo característica inerente a qualquer gênero textual, opta-se antes por uma configuração formal e por uma estrutura de conteúdos que pretende dialogar com professores do que por arranjos capazes de gerar novas possibilidades de diálogo com o jovem contemporâneo. Basta observar que os domínios discursivos mencionados antes são os mesmos desde a década de 1970, havendo mudança apenas entre os textos midiáticos, que ganharam, aos poucos, espaço maior nos livros.

O respeito a um modelo conhecido, por outro lado, parece ser determinante para o êxito das coleções. Basta observar que as três coleções responsáveis por cerca de $70 \%$ do conjunto de obras distribuídas, PL, NP e PCIS, contam com autores veteranos no universo editorial do livro didático. A coleção PL foi lançada ainda na década de 1980. O manual NP teve sua primeira edição em 1998, mas seus autores contam com obras didáticas produzidas antes. A primeira edição de PCIS é de 2000. Talvez não por acaso as críticas feitas no Guia/2015 (BRASIL, 2014) às coleções NP e PCIS se mostrem como traços da cultura do livro didático que chegou aos anos 2000: a insistência no tratamento de tipologias textuais, secundarizando a noção de gênero (NP), e a excessiva fragmentação dos textos (PCIS). A coleção PL tende a preservar a integralidade de boa parte dos textos, embora opte comumente por textos curtos.

Está entre as marcas da coleção PL a integridade dos textos de trabalho, com forte apoio imagético, como no caso das propagandas (ao lado da coleção PCIS, a coleção PL é a que mais investe em textos publicitários, além de tiras e outras imagens), fazendo desses gêneros uma ponte para o diálogo com leitores juvenis. Assim como na coleção NP, a disposição gráfica dos conteúdos é determinante. Os textos de terceiros são destacados em boxes distintos e também delimitados por cores próprias, ao passo que as demais coleções contam com menos marcas para delimitação entre os textos produzidos pelos autores e os textos de terceiros. Coleções como PCIS delimitam seus conteúdos por subtítulos (em grande número) e por marcações sutis: a tipologia empregada para a narrativa dos autores e para os textos de terceiros é quase idêntica, inclusive em relação ao tamanho das letras. Em outras coleções, a distinção entre textos dos próprios autores e de terceiros é discreta. Em SP, os textos de terceiros são delimitados por cores distintas, mas em fluxo contínuo. Nas demais coleções, as marcas divisoras são ainda mais tênues. 
A delimitação dos textos implica outro traço distintivo da coleção PL, como o que diz respeito ao fato de ser uma das coleções em que os textos aparecem mais bem situados. Embora a apresentação de boa parte dos enunciados seja feita com a indicação genérica de "texto", a coleção PL acaba por delinear com maior precisão cada um deles, consequentemente conferindo maior clareza à ideia de gênero determinado. Tal característica parece evidente no caso do que chamamos de verbetes. Enquanto na maioria das coleções, excertos de obras especializadas aparecem em soluções difusas, na coleção PL, tais inserções são, além de volumosas, mais bem delimitadas.

\section{CONSIDERAÇÕES Finais}

Mesmo não definitivos, os quadros anteriores permitem um olhar mais abrangente sobre os textos que circulam nos livros didáticos, estimulando constatações e inferências. $O$ panorama apresentado relativiza, por exemplo, argumento comum sobre os livros didáticos contemporâneos, como o de que a literatura perdeu espaço para textos cotidianos (cf. COSSON, 2014). Os números sugerem que os textos literários aparecem em quantidade expressiva, sendo a poesia e suas variações os mais presentes. Se se leva em conta o grande volume de obras de arte, cuja função primeira nas coleções é a de apoio à historiografia literária, o espaço ocupado por literatura e arte ainda é predominante.

O número reduzido de gêneros verbais e não verbais é também evidente. No caso dos textos não verbais, vários estão baseados na fotografia (cenas, fotos de autores, fotojornalismo, capas, reproduções de obras de arte e fotografias de pessoas e de objetos comuns). Entre os textos verbais, a diversidade de gêneros também é modesta, sobretudo se computados apenas os que estão presentes em todas as coleções. Faltam gêneros híbridos, por exemplo, evidenciados a partir do uso de novas tecnologias, como os baseados em vídeo, da telenovela aos textos que afloram a partir da popularização da web.

A partir do cenário apresentado é possível questionar o argumento apressado de que a escola apresenta poucos atrativos para os jovens de hoje. Embora a configuração dos livros sugira a permanência da tradição beletrista, boa parte das coleções e, sobretudo, as mais distribuídas, não é iniciante, num mercado ágil e sensível à recepção de professores, alunos, editores e do próprio mercado como um todo. Essas coleções são testadas ano após ano em performances reais (os números de venda), revisadas e atualizadas ciclicamente, acompanhando o tempo dos editais 
governamentais. Fazer supor o distanciamento desses livros do mundo dos estudantes significa, no mínimo, sonegar a experiência coletiva, continuada e altamente competitiva da qual essas coleções participam.

Assim, o fato de a coleção PL tratar, com mais quantidade e intensidade, de um conjunto pouco superior a uma dezena de gêneros maiores, pode contribuir para a ideia da monotonia escolar. Mas, sendo aquela coleção a preferida por boa parte dos professores brasileiros já há vários anos, e também pouco diferente das demais (em termos de gêneros empregados), isso pode supor a permanência de um roteiro mínimo que se sustenta na escola desde os anos 1970. Configura-se, então, característica importante para os dias de hoje, quando os conteúdos didáticos tendem a migrar do meio impresso para o meio digital e, principalmente, quando mudanças curriculares são feitas a canetada, desprezando a experiência escolar construída ao longo de décadas.

\section{REFERÊNCIAS}

ABAURRE, M. L.; ABAURRE, M. B. M.; PONTARA, M. Português: contexto, interlocução e sentido. São Paulo: Moderna, 2013.

AMARAL, E. et al. Novas Palavras. São Paulo: FTD, 2013.

BAKHTIN, M. Marxismo e Filosofia da Linguagem. São Paulo: Hucitec, 1992.

BRASIL, Ministério da Educação. Guia de livros didáticos: PNLD 2015: língua portuguesa: ensino médio. Brasília: Ministério da Educação, Secretaria de Educação Básica, 2014.

BRASIL. Secretaria de Educação Fundamental. Parâmetros Curriculares Nacionais - Introdução: $5^{\text {a a }} 8^{\text {a }}$ séries. Brasília: MEC/SEF, 1998.

BRASIL. Secretaria de Educação Fundamental. Parâmetros curriculares nacionais: terceiro e quarto ciclos do ensino fundamental: língua portuguesa. Brasília: MEC/SEF, 1998.

BRASIL. Ministério da Educação. PCNEM + Ensino Médio: orientações educacionais complementares aos Parâmetros Curriculares Nacionais. Brasília: MEC, 2006.

BRASIL. Secretaria de Educação Básica. Pacto nacional pela alfabetização na idade certa: o trabalho com diferentes gêneros textuais em sala de aula: diversidade e progressão escolar andando juntas: ano 03, unidade 05. Brasília: MEC, SEB, 2012a.

BRASIL. Secretaria de Educação Básica. Pacto nacional pela alfabetização na idade certa: o trabalho com gêneros textuais em sala de aula: ano 02, unidade 05. Brasília: MEC, SEB, $2012 \mathrm{~b}$.

BRONCKART, J. Atividade de linguagem, textos e discursos. Por um interacionismo sociodiscursivo. São Paulo: Educ, 1999.

CAMPOS, E.; CARDOSO, P. M.; ANDRADE, S. L. Viva Português. São Paulo: Ática, 2013. CÂNDIDO, A. Literatura e Sociedade. São Paulo: Ed. Nacional, 1985.

CEREJA, W. R.; MAGALHÃES, T. C. Português: Linguagens. São Paulo: Saraiva, 2013. 3v. CEREJA, W. R.; MAGALHÃES, T. C. Português: Linguagens. São Paulo: Saraiva, 2012. 4v.

COSSON, R. Círculos de leitura e letramento literário. São Paulo: Contexto, 2014. 
FARACO, C.A. Português: língua e cultura. Curitiba: Base Editorial, 2013.

FARACO, C. E.; MOURA, F. M.; MARUXO Jr., J. H. Língua Portuguesa: Linguagem e Interação. São Paulo: Ática, 2013.

MARCUSCHI, L. A. Produção textual, análise de gêneros e compreensão. São Paulo: Parábola, 2008.

MORATO, Edwiges Maria. O interacionismo no campo linguístico. In: MUSSALIN, F.; BENTES, A.

C. (Org.) Introdução à Linguística: fundamentos epistemológicos. v. 3, 5. ed. São Paulo: Cortez, 2011.

RAMOS, R. A. (Org.) Ser protagonista: Língua Portuguesa. São Paulo: Edições SM, 2013.

SCHNEUWLY, B.; DOLZ, J. Gêneros orais e escritos na escola. Campinas: Mercado de Letras, 2004. SETTE, G.; TRAVALHA, M.; STARLING, R. Português: Linguagens em Conexão. São Paulo:

Leya, 2013 .

\section{SOBRE OS AUTORES}

Juvenal Zanchetta Jr. é graduado em Letras (Faculdade de Ciências e Letras de Assis, UNESP), com mestrado e doutorado em Educação (Faculdade de Filosofia e Ciências de Marília, UNESP). É professor do Departamento de Educação da Faculdade de Ciências e Letras de Assis, UNESP. Tem experiência na área de Educação e Mídia e Prática de Ensino de Língua Portuguesa.

E-mail: zancheta@assis.unesp.br.

Keli Mazzo é graduada em Letras (Faculdade de Ciências e Letras de Assis UNESP), com Mestrado em Letras (UNESP, Assis). É doutoranda em Educação (UNESP, Marília) e professora de língua portuguesa da rede pública estadual paulista de Educação Básica. Tem experiência na área de Linguística, Literatura e Educação com pesquisa nos temas leitura e práticas pedagógicas.

E-mail: keli.mazzoo9@gmail.com.

Erika Nogueira Menegon é graduada em Letras (Faculdade de Ciências e Letras de Assis, UNESP), tem Mestrado e Doutorado em Educação (UNESP, Marília). É professora de língua portuguesa da rede estadual pública paulista. Tem experiência na área de ensino de linguagens, com pesquisa nos seguintes temas: ensino de gêneros textuais, leitura imagética e narratologia.

E-mail: erikamenegon@hotmail.com.

Recebido em 19 de junho de 2017 e aprovado em 15 de outubro de 2017. 